\title{
西藏高原对於东亞大氯環流 及中國天㴋的影响”
}

\author{
葉篤正顧震潮
}

(中甸科学院地球物理研究所)

如果我椚具体了解一下西藏高原的大小，我 归就能体会到它应該对东亞大氣環流及中國天氣 有巨大的影响。大玫來說它像個柊泪体, 东西長 軸在 3,000 公里以上，南北的筧度也遵到了 1,500 公里, 而西風帶的整個察度地不过䉆它的三倍 多。在垂直方向上它的平均高度到 4,001) 米以上, 佔揼了对流首 $1 / 3$ 以上的空間, 無疑地它是西風 帶中一個最大障㠜物，它一定足以使西風帶苌生 極大的撜動。

\section{一 西藏高原的綎種動力作用 和熱力作用}

当西風帶的位廽处於西藏高原的緯度帶時, 西藏高原就直接阻擋了酉風, 而成了西風帶中的 一俔阻擬物。这時空氣就不能自由地自上游流向 下游, 高原高度以下大部分空氣將向高原的兩边
分旺，繞着它过去。高原高度以上的西质帮也受

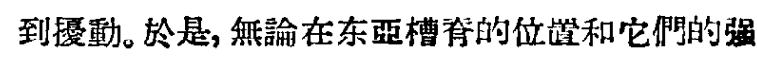
度 上、氣流的速度上以及对於下游的天氣上, 西 藏高湶就起了很大的影响。下面是西藏高原在东 亞環流和中國的天氣上,幾种具体的動力作用,

\section{L. 分支与会合作用}

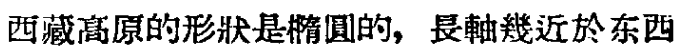

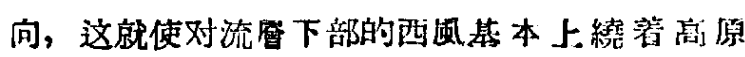
流过分成南北兩支, 如圖 1 所示。但是这种作川 不僅限於任空，它可以到達对流管伯以上（所以 到達这栤漓的源因, 可能与西藏高原上的皘雪有 關，因皘等大量敬熱，温度降低，於是与它的南

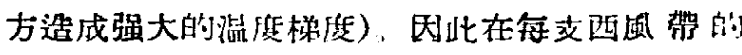

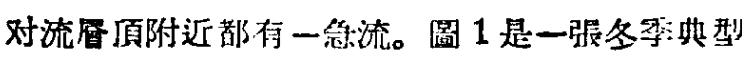
300 裏巴等高線菭，它大致表示了 10 公里上空的 氣流情况，在这張喝上问風帶在高原上空分支現

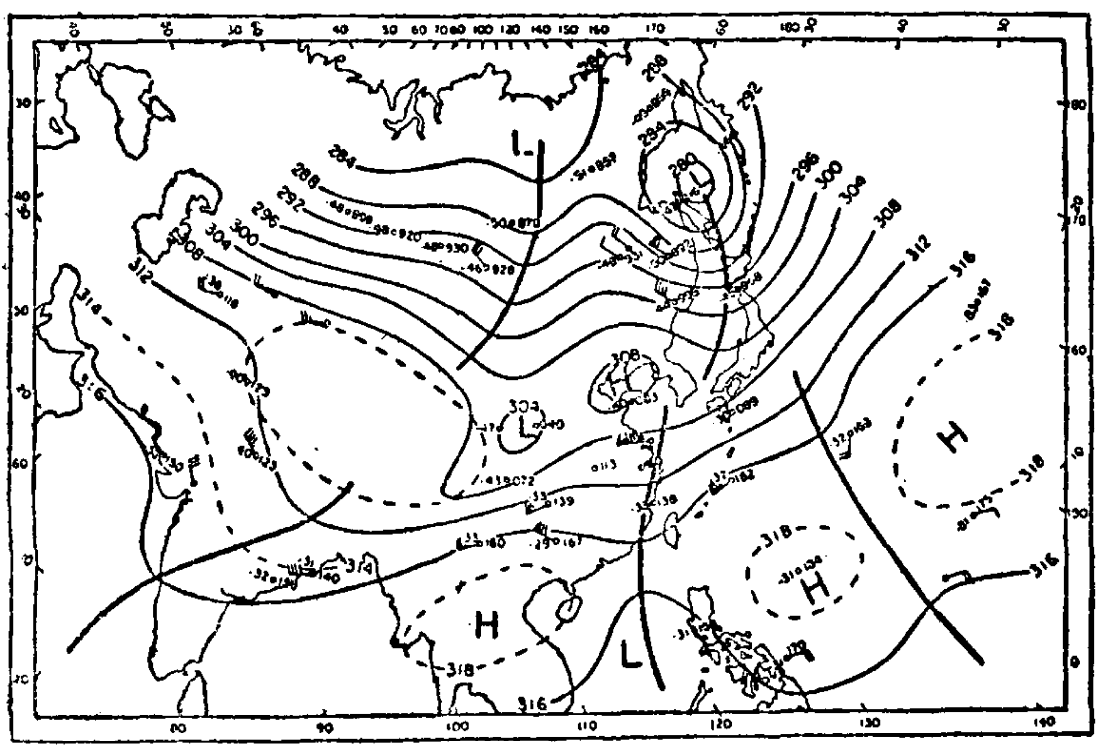

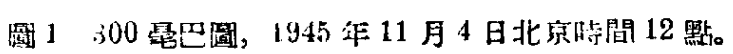

緗示得極第清楚。在这

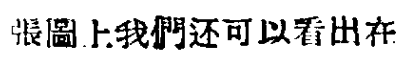
西藏高原分成兩支的急海 在日本与寄又復会合越 來, 形成了北牛球报强大 的西風急流, 它的强度奖 比北美东岸的急流强胙 多。置 2 第沿东縞 $120^{\circ}$ 1945 年 12 月和 1946 年 1

“本交係俰作者於 1955 年 6 月在中國科学院学部成

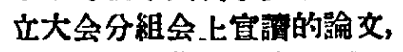
峧婊時曾經作者略 加删械。

一耤者
6 月号

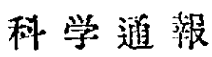




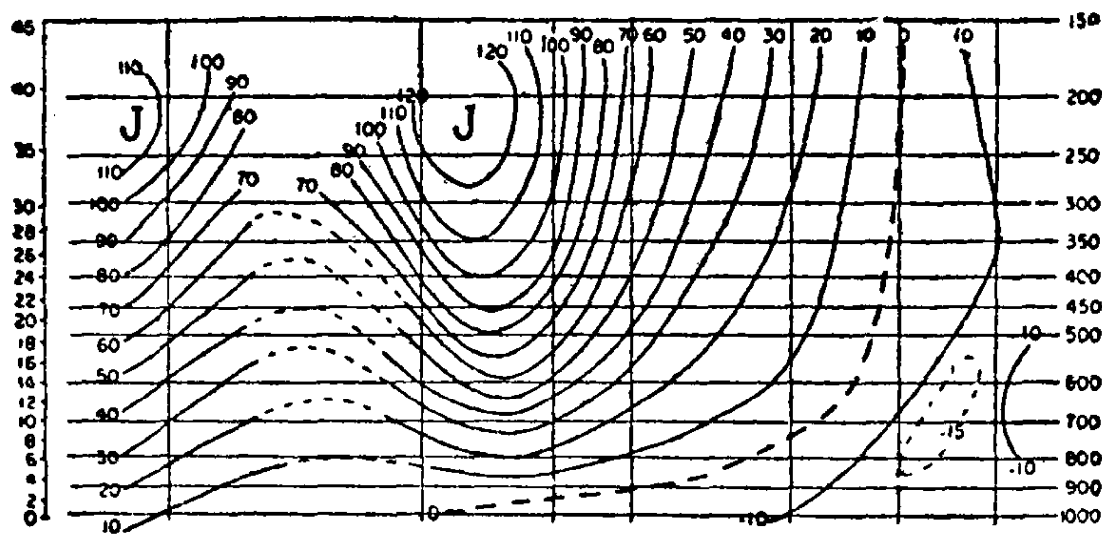

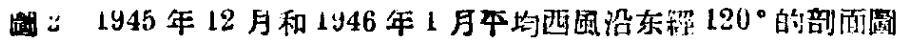

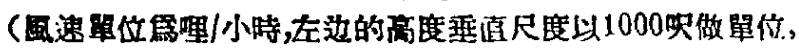

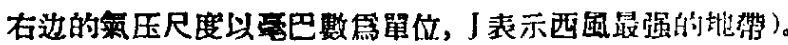

揞带雨水的氣压泉統是 受着西風操緃的進的。

至於北支西京則不 但强度微弱，而且位鼓 弶化很大。南北兩支西 蛔的不同是容易解霓

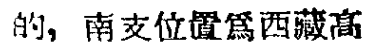
京所規定，而北支則可 自由移䣦。

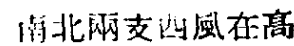
原为边的会合，在找國 的天氣上起着巨大的作

月平均西風風速剖面榃，圖中明欵地指出丁兩支 急流的存存，它門的高度都在 220 毫巴(12公里) 附近，一個在北緯 28-29 ${ }^{\circ}$ 之間，另一個在北緯 $40^{\circ}$ 以北。在中获細亞或沿东經 $76^{\circ}$ 我們也可以

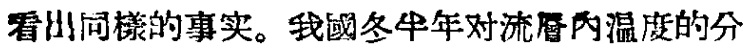
析, 世祝明兩個急流的事实。

根操观測，南支西風急流非常强大而且獣 定。侧如在 1945 -46年冬季沿东称 $120^{\circ}$ 西風分 佈随時間的䜌化裡，这支等流的平均位置在北

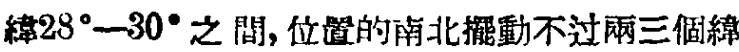
度。这支急流的稳定性在我國南牛部的降丽起着 很大的作用，比㜞策侯圖桇中的冬季各月的雨量 分作和南支急流在空間的分作（圖 3)，我們可以

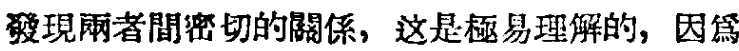

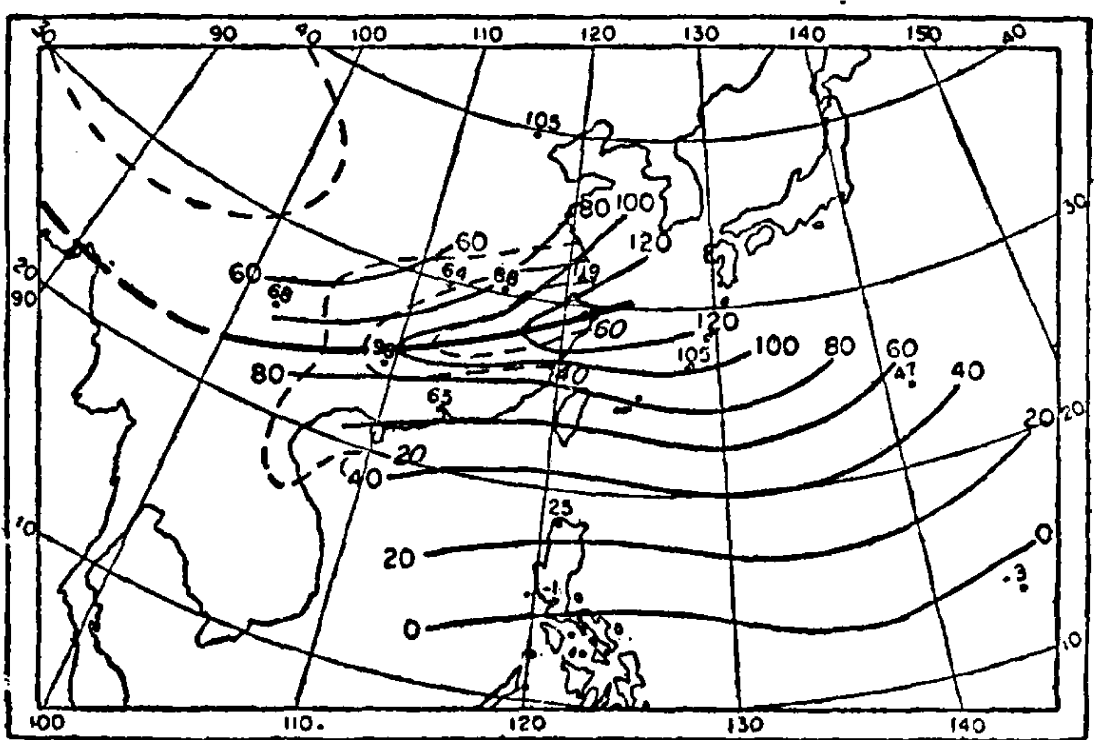

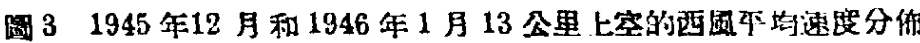

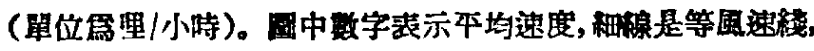
粗綪表示西国急流的位粗。

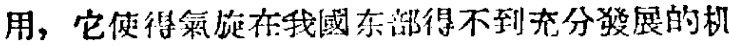

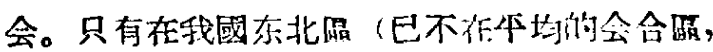

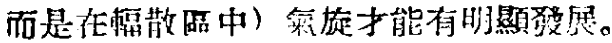

2. 抑制作用及生成作用

我國天氣工作者都有一储然同的經输，就是

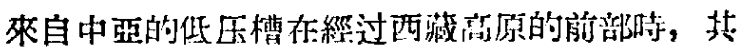
品度常常要减弱。在冬季, 当一個南北向的大槽 走近高原時，其南部常常被切斷，停於湢原约西 側，其北部可以向下游东去，河時强绩减弱，只

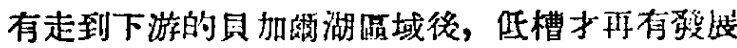

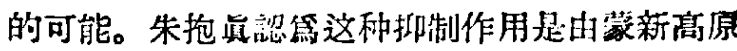
而非酒藏高原本身的作用，但至少都是大地形们 殿响。此种作用可称抑制作用。对於高区籍和高 压來說，接近高原時賞有明慜的加强的作用。

另一观测事实就是在 我國东部，龙其在長江 以南，600 毫巴（約 4 公里）以上的敦聜風非 常稳定，其方向䑢乎正 西。長江流域愿年冬牛 年的院空風, 可以需作 一個例子。这湖事实說 明很少有大系統可以通 过高原。然而必須指 出, 由西藏高原上空过 不少的, 甚否西風帶特 別编南的僻影复季赛, 也有这种系統过來。

但是, 另一方䣼，由 於地形的㨡動文可以在 


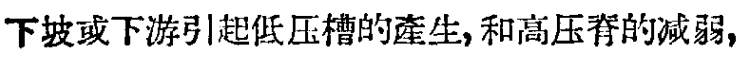
我門知道在河西一帶酸北支裹面是容易座生低 区槽（西北低槽）的。非恒定問題的簡單計算結 果証明，在东亞实際地形的擾動下，本直西風、 風速每秒 10 米時, 河西和四川一帶 500 毫巴等 区面就有每 24 小時 50 米的窝 度戀化（約 相当 於地面氣压每 24 小時降 6 個毫巴，其他風速下 可按比例推算, 但風向相反時氣压變化符号也相 反), 就有形成西北低槽和西南低渦的可能(圖4)。 而且在風向有偏北成分時, 河西地品發生增压

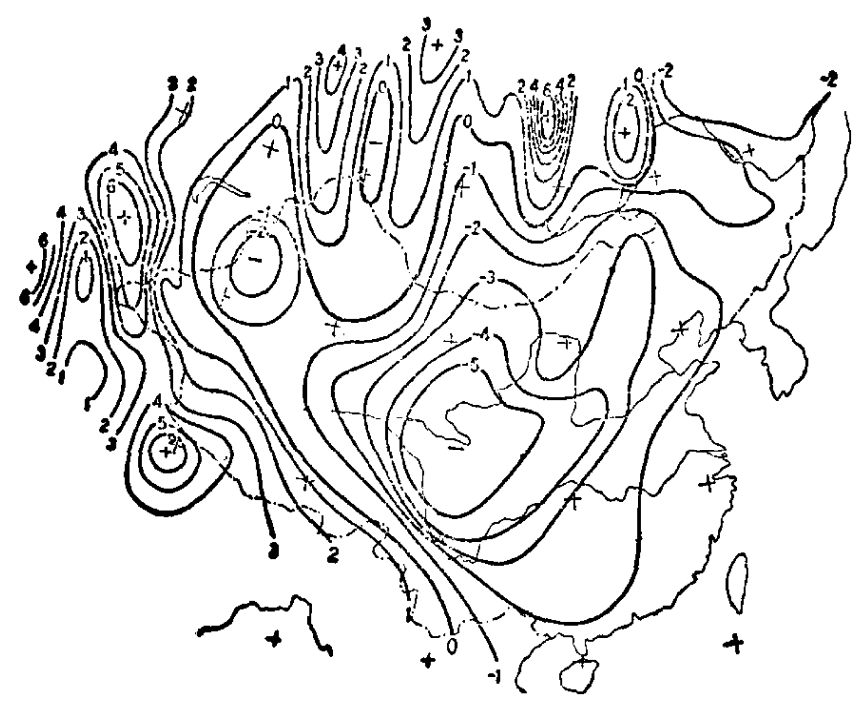

可 4 氣流越过高原時輻散輻合所造成的 500 影巴等压 面高度變化 (單位: 10 米/24 小洔)，西通等秒 10 米時的情形(根㨡实際的地形)。

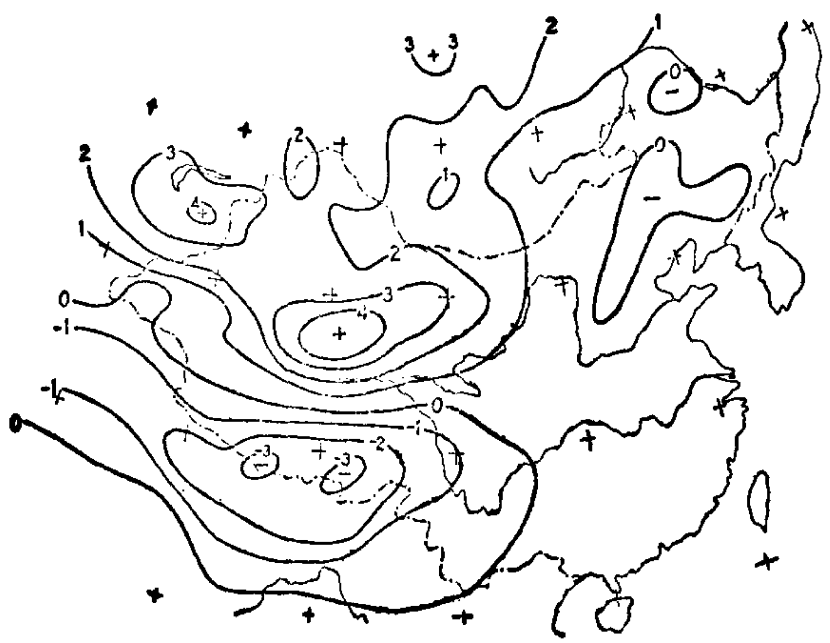

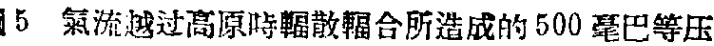

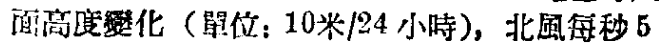
米時的情形(贷據实際的地形)。
（圖 5）比較大，所以在風向比較偏北時，西北 不易由於地形对氣流的授動而形成低槽，这也是 与事实比较符合的。此外，在南支西風中，有時 也有低压槽从印度、緬甸一帶体來。

地形的楽動的經常的存在，使緯图環流終於 要相应地改綎, 因此在平均情况下（恒定情形）, 在高原中間的經度上北边会有嵪压脊，南部会有 低槽，同時下游在日本附近还有一個大槽。在冬 季, 新疆、蒙古上空的这個高压脊是和地面蒙古高 压有關联的，印度孟加拉裂的平均槽更对冬牛年 我國南部的降水有着很大的關係，並且造成 高原东緣冬季的对流性天氣。日本的低槽强 度很大，这裹面海陸分作可能也是有很大作 用的。

\section{3. 屏障作用}

由於高原的屏障在高原的东側有一 “死 水”淐形成，在这區中摄動少，風力微弱。 根握1944-1945年的覌測，在新津 3 公里以 下即使在冬季風速也不超过每秒 $4-5$ 米。在 冬牛年常常有一層薄的冷空氣存留在这激域 裹。这層經常存在的冾空氣与所罚的“昆明 准静止鋒”侍愍切䈘係。圖 6 是新渄 1945 年 1 月份平均上种曲綫，这個上外䋐有着明 㙷的逆温墔，它的厚度平均是70 琵巴 (700 -630 毫巴約朴当 700 米厚)。强度遵 $8^{\circ} \mathrm{C}$ 。 这可能就是淮靜止鋒的逆温層。这個静止鋒 䍃透成貴州一帶壞天氣的直接原因。

在“死水”區內風力踓然微弱，但是不同 大小的小瀜旋則經常可以覌測得到，然而它 們是不發展的。由於高原背風側氣流輻合區 的存在, 除非北面有其他采統的影响, 这些 小渦旋離開这個區域东去時就在高原後方的 輻合區裏消減了。

\section{4. 西藏高原的熱力作用}

大信原的存在也直接改變了自由大氣的 温度場而影响運動場。

日間高原吸收日輻射大於四周自由大 氣，夜間高原的散熱也大於四隔的自由大 氣，於是高原与四周自由大氣間的温度梯度 就有着明顯的巨大的日笅化。这种溜度梯度 的日夜筱化將在高原四周应生一种与海陵風 相似的風力日数化，在下淈吹向高原，夜
6 月号

科 学通報
- 31 . 
間風自高原吹出。这現象在新津等地一天二次的 雷達測風紀錄上可以看得很清楚。而根握近年來 的覌測，这种風力日数化的存在不僅僅限於某一 個季節，而是終年存在的。在垂直方向並且可達 6 公里以上。在印度牛島上的情况也是如此。高 原对於風力日葚化的这种作用在印度牛島北部上 空可遠達二三百公里以外的測站。如以对离原的 幅合或輻散强度來表示西藏高原对四周地面風力 日督化的作用，則在下午風力对高原的輻合量級

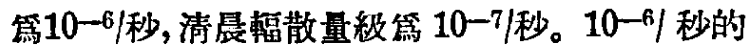
大規模輻合的量級是一個很可覌的數值, 这一點 就可以說明西藏高原对於大氣環流影响之大。

西藏高原的存在也造成了高原上空大氣温度 的巨大年策化。在夏季裹高原上的大氣是同緯度 最熱的。在 500 毫巴經常有西藏高压的存在。这 些暖空氣和暖高压的东移，直接影响了我國东部 夏季的天攻过程。在冬季裹, 高原中部輻射冾却 又特別厲害，加强了高原南边的西風南支。

\section{二 高原動力作用的季節学化}

除去高原对於風力日数化的作用外，前章所

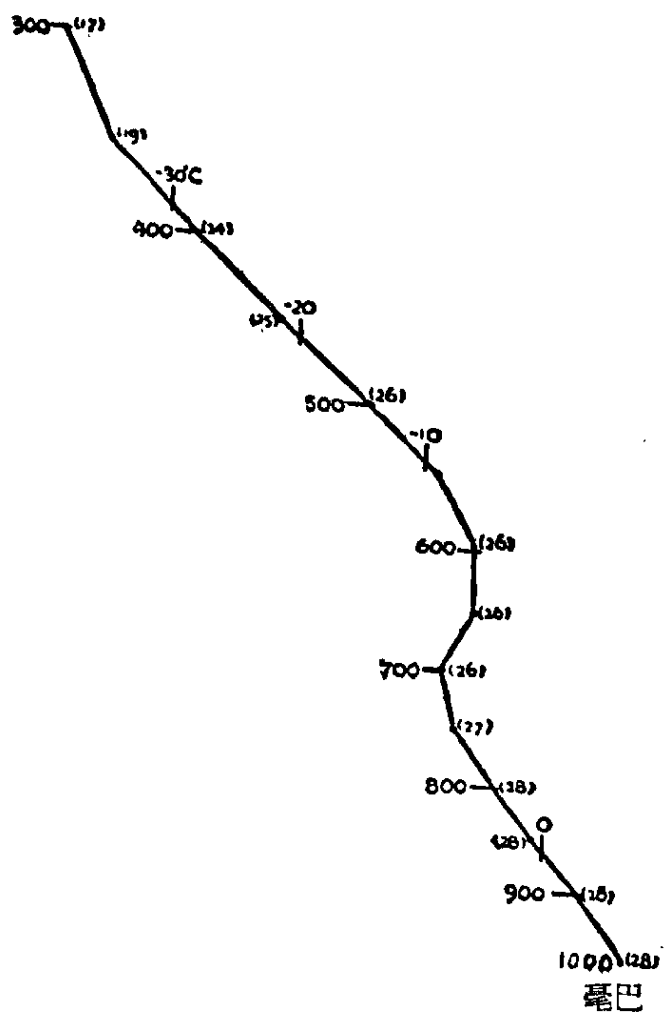

國 6 新津高空平㚬滥度分佈（1945年1月份） （括易內數字是探湘呢錄總數）
时論的現象主要䝢現於冬季牛年，到了夏季西栭 帶北移，高原不復在西風帶的主要部份中，於是 情况就和冬季不同了。有些歐洲的氣象学者, 如 Bolin 和 Sutcliffe, 認䉆地形对於大氣環流的 影响是不變的，因篇汀脈是固定在富間不的。 这是不对的，地形的動力作用是和流过山地的 氣流緊密地联系着的，地形踓然固定不動，而流 过山脈的氣流結構則有着極大的季節綎化，这 就使得地形的動力作用也有着季 節等 化。根 譃 1945一-1946年的記錄, 南支急流在 10 月中很突然 地生成了, 10 月中以前昆明和芷江 600 毫巴以上 的風速沒有超过每秒 20 米的，而就在 10 月中的 这幾天，600 毫巴以上的風力很块地就增加到了 每秒 30 米以上,这表示西風南支急流在这時闍內 生成了。生成後其强度逐㴬增大，至篇冬洼最大。 此後强度漸减, 至 5 月底突然消減。隨着南支急 流的消失，夏季風在我國得以迅速地北上，这表 現在湜度上就有個急形。近地面 5 公里的中氣柱 的平均温度在高原的东边自 5 月到 6 月也有同様 的一個迅速的增加，这個坻加超过同時撕內北牛 球任何其他地區的温度鉴化。值得注悹的是南支 急流的迅速消減篇东亞大氣環流中的一㑑正謷季

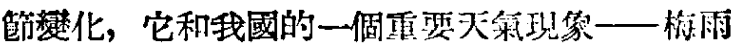
也是联系着的。

当西風帶北移後，西風的主要部分不復通过 高原，於是在夏季西風分支的現象不再出現。这 時我們所有的乃是西南季風自印度洋北上，流向

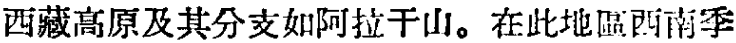
風被迫旋轉，而在印度东部形成氣旋渦挍，这個

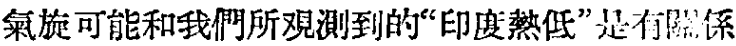
的。無疑地印度低压是個熱低，然派它不一方是 純熱力的。就連印度西部温度更高一些的地力, 低压的形成也有動力性的因素。現在我們知过 在温度分佈上复季最高温度在阿拉伯，而印度高 空低压則在印度牛島东部，这就是譙“印度 熱 低 压”的生成可能有動力的因素。在这方面 Benerji 也有類似的意見。

当西風帶在夏季北移後。在冬季所經常观测 到的抑制和屏障作用也就消失了。

\section{三繦結}

过去在談到地表面对於大氣環流和天氣影响 


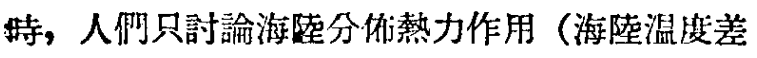
異的非緯向分作）的影响。由上面的討論我們看 出过去的看法是不够的。由大高原地形所引起的 動力作用以及熱力作用的重要性也是巨大的。而 且大氣環流是在熱力和動力共同作用下而生成的 一個總体, 这兩個作用是息息相關的。冷熱差暴 是大氣運動的基本矛盾。然而反过來当天載过程

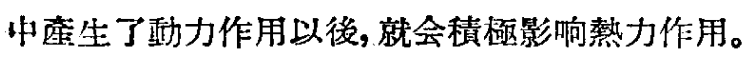
人們常常䝠意問什麼是動力生成的, 什究是熱力 生成的。这是我們应該知道的。可是更重要的是我 門应該精確了解这兩种作用是如何的相互關联、 相互制約, 以及在它們相互作用下, 大氣環流和天 氣过程会産生什麼結果。这是需要氣管学者們在 動力氣象及天妞学上媣入研究的一個重要問題。

附註，本文篇下列數文之總結

篤正: Circulation of the high troposphere over
China in winter 1945-46, Tellus, 1950 .

The seasonal variation of the influence of Tibetan Plateau on the general circulation, Science Record, 1952.

䈎篤正, 高由䄚, 刘医南: A study of the onset and retreat of the jet stream over Southern Asia and southwest U. S. A. in 1945-46, Jour. Chinese Geophy. Soc. vol. 2, 1951.

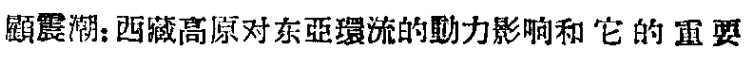
生, 中國科学, 第 2 然, 第 3 期, 1951 。

The structure of the upper wind over Western China in winter, Science Record, vol. $4,1951$.

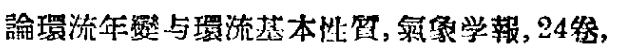
第 2 期, 1953 。

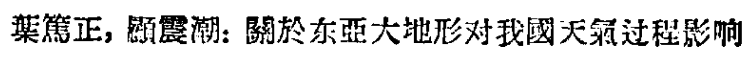
的幾個事实和計算(即將攱表)。

\section{[上接 72 具〕}

况出愎, 饤出比較長期的和每一時期的自学計劃 (学昜中並由高級人員給予輔導)。这一种方式不 但对能使每一幹部明確自己的努力目標和步驟, 可以在一定程度上克服其学想的爱踩情緒; 另一 方面, 由於这是服从研究所的發展計尲的, 也就 能推動研究所工作的前進。

（2）必須注澺結合工作來淮行培美。但結 合工作淮行培养决不能流於空談，实際上不閔懹 年青幹部的培养, 决不是对幹部的成長听其自生 自滅。因此, 領導人员在思想上必須明礁“培养毒 年科学幹部, 爲目前全部科学工作墁中心的任 務”的深刻意義。要十分湿愠幹部的成長, 在一切 工作上針对每一幹部的不同特點，探取各和各樣 的办法去積極培养幹部。並且留尽可能对每一幹 部的成長事先作出一個估訫, 也就是說要大体上 要有一個計劃。另一方面青年同志必須大力克服 急路情緒和單純依賴領導的思想, 要虚心学柏和

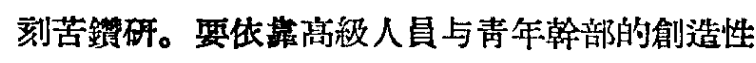
的合作, 做到郭沫若院長所提出的“使团結 科学 家的工作和科学幹部的培养工作能够統一地, 正 確地予以实現。”

（3）过去各研究所一般在思想上对研究实 習員的培养是比較明確的，但有的同志对培养助
理研究員的覌點往往較第淡薄, 这是必須改進 的。目前我國副研究員以上的高級研究人員管數 不多, 遠难適应國家努設的需要, 这不独优國家

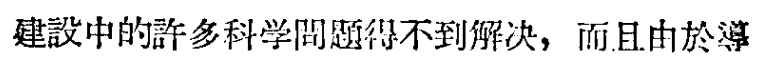
師缺乏，也影响到培养青年翰䘜的數量。所以加 强对助理研究是的培荂工作, 对科学事業的墢㧱 關综很大。

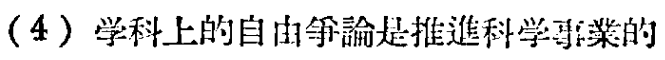
重要武器。从培养幹部工作角度來看, 開展学術 討論, 增强学術空氣, 也是幹部成長过程中所必 需的優良環境。骤毒年幹部壆加学術討諭会, 可 以使之学会如何深入思考, 銓研問題, 發現問题 和提出問題; 也可以使之在自己專業範園內筑会

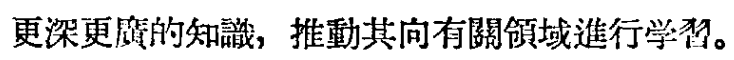
但 1954 年中上海各研究所学術討論的氣氛还是 不够浱厚, 需要進一步努力的。

（5）培养幹部的檢查制度也必須㩔 格起 來, 研究所对於每一幹部的学晳与工作应有定搠 的检查与考核。適当的晉級与獎殿的制度对培养 幹部也有皘極的意義。目前有的研究所对研究人 員的研究論文和工作報告还缺乏嚴格的考核与評 諭的版度, 今後也是需要改非的。
6 月号

科学通郝 